\title{
Chuquiraga spinosa Lessing: A Medicinal Plant for Gastric Cancer Induced By N-Methyl-N-Nitroso-Urea (NMU).
}

\author{
Jorge Luis Arroyo-Acevedo', Oscar Herrera-Calderon ${ }^{2 *}$, Juan Pedro Rojas-Armas ${ }^{1}$, Victor Chumpitaz-Cerrate ${ }^{3}$, \\ César Franco-Quino ${ }^{3}$, Renán Hañari-Quispe ${ }^{4}$
}

\begin{abstract}
Jorge Luis Arroyo-Acevedo ${ }^{1}$, Oscar HerreraCalderon ${ }^{2 *}$, Juan Pedro Rojas-Armas ${ }^{1}$, Victor Chumpitaz-Cerrate ${ }^{3}$, César Franco-Quino ${ }^{3}$, Renán Hañari-Quispe ${ }^{4}$

'Laboratory of Experimental Pharmacology, Faculty of Medicine, Universidad Nacional Mayor de San Marcos, Lima, PERU.

${ }^{2}$ Faculty of Pharmacy and Biochemistry, Universidad Nacional San Luis Gonzaga de Ica, Ica, PERU.

${ }^{3}$ Laboratory of Physiology and Pharmacology, Faculty of Dentistry, Universidad Nacional Mayor de San Marcos, Lima, PERU.
\end{abstract}

${ }^{4}$ Laboratory of Animal Physiology, Universidad Ándina Néstor Cáceres Velásquez, Puno, PERU.

\section{Correspondence}

\section{Oscar Herrera-Calderon}

Faculty of Pharmacy and Biochemistry, Universidad Nacional San Luis Gonzaga de Ica. Ica, PERU.

Phone no: +51956550510

E-mail: oherreracalderon@gmail.com

\section{History}

- Submission Date: 27-06-2017;

- Review completed: 17-08-2017;

- Accepted Date: 03-09-2017

DOI : 10.5530/pj.2018.1.4

Article Available online

http://www.phcogj.com/v10/i1

\section{Copyright}

(C) 2018 Phcog.Net. This is an openaccess article distributed under the terms of the Creative Commons Attribution 4.0 International license.

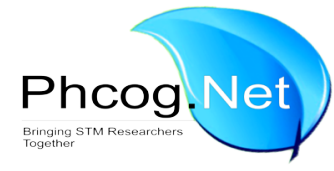

\begin{abstract}
Background: Gastric cancer (GC) is one of the most frequent diseases in human population: Many plants from Peruvian flora is used to treat cancer as alternative treatment. Chuquiraga spinosa Lessing (ChS) is a species with high potential therapeutic due to its antioxidant and anti-inflammatory effect as well as protective against prostate cancer. Objective: The main objective was to evaluate the possible protective effect of Chuquiraga spinosa extract on NMU (N-methyl-N nitrosourea)-induced gastric cancer in rats. Methods: Gastric carcinogenesis was induced in 30 male Holtzman rats by providing NMU $50 \mu \mathrm{g} / \mathrm{Kg}$ by oral administration for 16 weeks. Ethanolic extract of ChS aerial parts was administered at doses 50, 250 and 500 $\mathrm{mg} / \mathrm{Kg}$ per oral. The protective effect was determined through weight controls, biochemical and hematological parameters; the antioxidant capacity by superoxide dismutase (SOD), nitric oxide (NO), malondialdehyde (MDA) and anti-inflammatory capacity by the level of C-reactive protein (CRP). The tumors were monitored by using histological examinations. Results: Oral administration of Chuquiraga spinosa extract significantly decreased superoxide dismutase malondialdehyde, nitric oxide, C-reactive protein levels $(p<0,01, p<0,01, p<0,01$ and $p<0,01$ respectively compared with Inductor group). There was a significant increase in the weights of animals $(P<0.05)$. Conclusion: Considering the anti-inflammatory, antioxidant, and anticancer properties of Chuquiraga spinosa extract, we conclude that it has a protective effect on NMU induced gastric cancer in rats.

Key words: Chuquiraga spinosa, Anticancer, Anti-inflammatory, Antioxidant; NMU.
\end{abstract}

\section{INTRODUCTION}

Gastric cancer is the third cause of death in the world ${ }^{1}$ Gastric surgery including systemic lymph node dissection is the current protocol of treatment for gastric cancer. Recent researches have shown that the overall 5-year survival rate of gastric cancer has improved with gastrectomy and chemotherapy. ${ }^{2}$ The annual incidence of cancer in Peru is approximately 150 cases for 100.000 habitants and 45.000 new cases each year in according to the National Institute of Neoplastic Diseases (INEN). ${ }^{3}$ Currently, the major percentage of diagnosed cancer is determined in the final or advanced stage, reaching $75 \%$ of diagnosed cases. ${ }^{4}$ These facts bring a low curability, poor life quality, an elevated cost of treatment and a high mortality rate. ${ }^{5}$ Bioassays in animals play an important role to understand gastric cancer pathophysiology. Various etiological factors for gastric cancer, such as salt, nitrates/nitrites, and nitrosamines are known to induce gastric cancer. ${ }^{6}$ These synthetic N-nitroso compounds, like N-methyl$\mathrm{N}$-nitrosourea (MNU), which has been used in experimental gastric carcinogenesis can induce DNA mutations, and is also known to modify amino acids in histone proteins leading to chromatin remodeling. ${ }^{7}$
Many medicinal plants are used by patients with cancer due to numerous positive effects on pain relief, vomiting, nauseas, depression, and anxiety. ${ }^{8}$ Bioactive compounds such as polyphenols, tannins, flavonoids can have antioxidant capacity with potential benefits for health and could reduce cancer risk, it has been demonstrated that the anti- inflammatory effect of these compounds inhibit arachidonic acid (AA), prostaglandins, and leukotrienes. ${ }^{9}$ Polyphenols are chemoprotectives that act by blocking of initiation stage of carcinogenesis, free radicals and activation of glutathione peroxidase, glutathione reductase and inactivation of glutathione $S$ transferase. ${ }^{10}$

Chuquiraga spinosa (ChS) Lessing (Family: Asteraceae) is called "huamanpinta" and is a species with therapeutic properties from Peruvian flora. The stem and leaves infusion of this plant is used for its antiinflammatory effects and urinary infections. Previous studies have reported that $\mathrm{ChS}$ presents anti-inflammatory and antimicrobial effects. ${ }^{11}$ The main objective in this research was to determine the protective effect of aerial parts of Chuquiraga spinosa on NMU induced gastric cancer in rats.

Cite this article: Arroyo-Acevedo J, Herrera-Calderón O, Rojas-Armas J, Chumpitaz-Cerrate $\mathrm{V}$, Franco-Quino C, Hañari-Quispe R. Chuquiraga spinosa Lessing: A Medicinal Plant for Gastric Cancer Induced By N-Methyl-N-Nitroso-Urea (NMU).. Pharmacog J. 2018;10(1):20-4. 


\section{MATERIALS AND METHODS}

\section{Animals}

A total of 30 rats Holtzman $(150 \pm 20 \mathrm{~g})$ of male sex were obtained from the National Institute of Health (Lima, Peru). Rats were kept in plastic cages with access to pelletized food and water ad libitum and housed in animal room with controlled temperature $\left(22-24^{\circ} \mathrm{C}\right)$ and $12 \mathrm{~h} \mathrm{light} /$ dark cycle. Rats were divided into five groups of six animals each and acclimatized to the laboratory 15 days previous to the experiments. All experimental procedures involving animals were conducted in accordance to the guidelines established by the European Union on Animal Care (CCE Council 86/609) and approved by the Institute for Ethics in Health of the National University of San Marcos (01414-R-12-UNMSM).

\section{Chemicals}

$\mathrm{N}$-methyl-N-nitroso-urea (NMU), sodium nitroprusside, sulfanilic acid reagent, thiobarbituric acid (TBA) and trichloro acetic acid (TCA) were purchased from Sigma-Aldrich, USA.

\section{Plant material}

Chuquiraga spinosa was collected, in January, 2016 from Huancayo, Peru, and identified by Hamilton Beltran. A voucher specimen (152USM-2016) was deposited at the National Herbarium of National University of San Marcos (UNMSM), Lima, Peru.

\section{Extraction of plant material}

The aerial parts of Chuquiraga spinosa (1000 g) were dried at room temperature and pulverized at the Chemical Laboratory, Faculty of Pharmacy and Biochemistry, Universidad Nacional San Luis Gonzaga de Ica (UNICA), the powder material was exhaustively soaked with 96 $\%$ ethanol and intermittent shaking every day for 7 days. The extract was filtered and evaporated by using a rotavap. The crude ethanolic extract obtained (20 g) was stored until further studies.

\section{Phytochemical Screening}

The presence of phytochemical constituents, such as alkaloids, terpenoids, quinone, flavonoids, tannins, saponins, steroids and phenolic compounds were determined with the standard qualitative phytochemical methods described. ${ }^{12}$

\section{Protective effect on NMU induced gastric cancer in rats Tumor induction}

In all groups, except negative control and NMU groups, tumor induction was carried out by following the method of Tatematsu et al. with brief modifications. ${ }^{13} \mathrm{NMU}$ was used as carcinogenic agent for gastric cancer induction. Animals received a single dose of $500 \mu \mathrm{g} / \mathrm{Kg}$ of NMU dissolved in saline solution $\mathrm{pH} 5.0$ by oral administration.

\section{Experimental design}

30 males Holtzman rats were divided into five groups of 6 rats each. Groups were placed according to the treatment and dose in $\mathrm{mg} / \mathrm{kg}$. ChS refers to Chuquiraga spinosa ethanolic extract. The negative control group received polysorbate $803 \%$ orally for 16 weeks. Group NMU was induced with NMU on the first day and received polysorbate $803 \%$ and NMU $500 \mathrm{ug} / \mathrm{Kg}$ orally for 16 weeks. The groups NMU + ChS 50, NMU + ChS 250, and NMU + ChS 500 received Chuquiraga spinosa (50, 250, and $500 \mathrm{mg} / \mathrm{kg}$ body weight, respectively) orally for 16 weeks with NMU induction.

At the end of the experiment, rats were weighed. Blood samples were collected to assess the biochemical parameters and hematological indicators. The animals were sacrificed by using pentobarbital anesthesia $(100 \mathrm{mg} / \mathrm{kg}$ ). The protective effect was determined through weights as well as biochemical, hematological; the antioxidant capacity by superoxide dismutase (SOD), ${ }^{14}$ nitric oxide (NO) ${ }^{15}$ malondialdehyde (MDA) ${ }^{16}$ and the anti-inflammatory capacity by the level of C-reactive protein (CRP).$^{17}$ Histological analysis. Stomach were removed and fixed in $10 \%$ formalin, processed, and embedded into paraffin blocks. Sections were cut at 5 $\mu \mathrm{m}$ thickness and stained with H\&E (hematoxylin and eosin). The slides were examined under a light microscope (Olympus BX51).

\section{Statistical analysis}

Data are presented as mean \pm standard deviation (SD). Data were analyzed for homogeneity of variance by the Levene test and normality by the Wilk-Shapiro W statistics. One-way analysis of variance (ANOVA) followed by Tukey multiple comparison method was carried out to compare the mean value of different groups. A P-value of 0.05 was considered statistically significant in all cases. Data were analyzed by using SPSS v. 21.

\section{Ethical considerations}

During the experimental process, international ethical principles for research using laboratory animals were respected. The rats were euthanized by intravenous injection of pentobarbital $(100 \mathrm{mg} / \mathrm{kg})$. This method leads to a quick and peaceful death, acceptable for rats.

\section{RESULTS}

Table 1 shows the secondary metabolites present in the ethanolic extract of aerial parts of Chuquiraga spinosa. The ethanol extract exhibited flavonoids followed by terpenes and alkaloids.

Figure 1. The morphology of the rat stomach was observed by microscopy. Moderated dysplasia was found in all groups treated with NMU. The group NMU + ChS50 showed moderated dysplasia. However, NMU $+\mathrm{ChS} 250$ had the lowest incidence. All the groups treated with ChS had lower incidence of inflammation and dysplasia. NMU + ChS500 showed the best protective effect on NMU induced gastric cancer.

Figure 2. In regard to weights of experimental animals a significant increase of body weight was found in all groups treated with ChS. However, NMU + ChS500 had the highest value with regard to NMU group. Hematological indicators show that the triglyceride level was significantly lower in group NMU + ChS250 and group ChS500 $(\mathrm{P}<0.05$ and $\mathrm{P}<0.01)$ than in group NMU. Administration of ChS at doses of $500 \mu \mathrm{g} / \mathrm{kg}$ significantly increased the level of HDL $(\mathrm{P}<0.01)$ (Table 2).

Biochemical indicators showed that the SOD, NO, MDA and CRP level was significantly lower in group NMU+ChS250 and group NMU + ChS500 ( $\mathrm{P}<0.05$ and $\mathrm{P}<0.01)$ than in group NMU. Administration of Chuquiraga spinosa at the dose of $50 \mathrm{mg} / \mathrm{kg}$ significantly reduced the SOD level $(\mathrm{P}<0.05)$ as compared with group NMU (Table 3$)$.

\section{DISCUSSION}

NMU is a tumor agent which has a high affinity by $\mathrm{H}_{2}$ than $\mathrm{H}_{1}$ receptor, furthermore these receptors show different systems of second messengers, producing cell proliferation such as in differenced and transformed cells. NMU produces hydrolysis of inositol phosphate mediated by phospholipase $\mathrm{C}$, subsequently efflux of $\mathrm{Ca}^{++}$and protein kinase $\mathrm{C}^{18}$

Dysplasia is more biologically related to malignant transformation of gastric mucosa and in this study, all animals that received the tumorinducing agents showed great dysplasia especially in the group that not received treatment. ${ }^{19}$ The age possibly influenced that dysplasia was the predominant pattern. ${ }^{20}$ In our study, the rats were 4 months (young adults) which allows their tissues respond less aggressively. The histological pattern found in the rats given ethanol extract of Chuquiraga spinosa showed discrete dysplasia with fibrotic areas. ${ }^{29}$ 

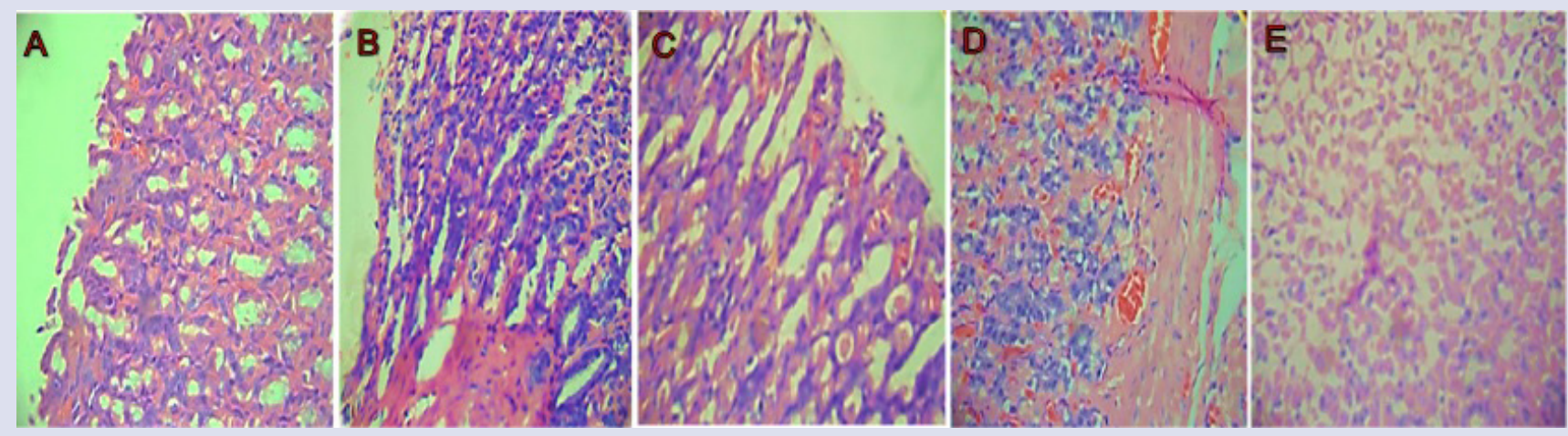

Figure 1: H\&E staining of stomach of control and experimental animals. (A) Negative control: Normal stomach $\times 400$. (B) NMU: Moderated dysplasia (a) infiltrated muscularis mucosae, picnotic nucleus, (b) congestion, (c) fibrosis, $\times 400$. (C) NMU + ChS50: Moderated dysplasia (H\&E) $\times 400$. (D) NMU + ChS250: Moderated dysplasia: (a) erosion in apex, lymphocytes and macrophages infiltration in submucosa area (b) nucleus in different shapes and sizes $(H \& E) \times 400$. (E) NMU + ChS500: moderated congestion in apex $(H \& E) \times 400$.

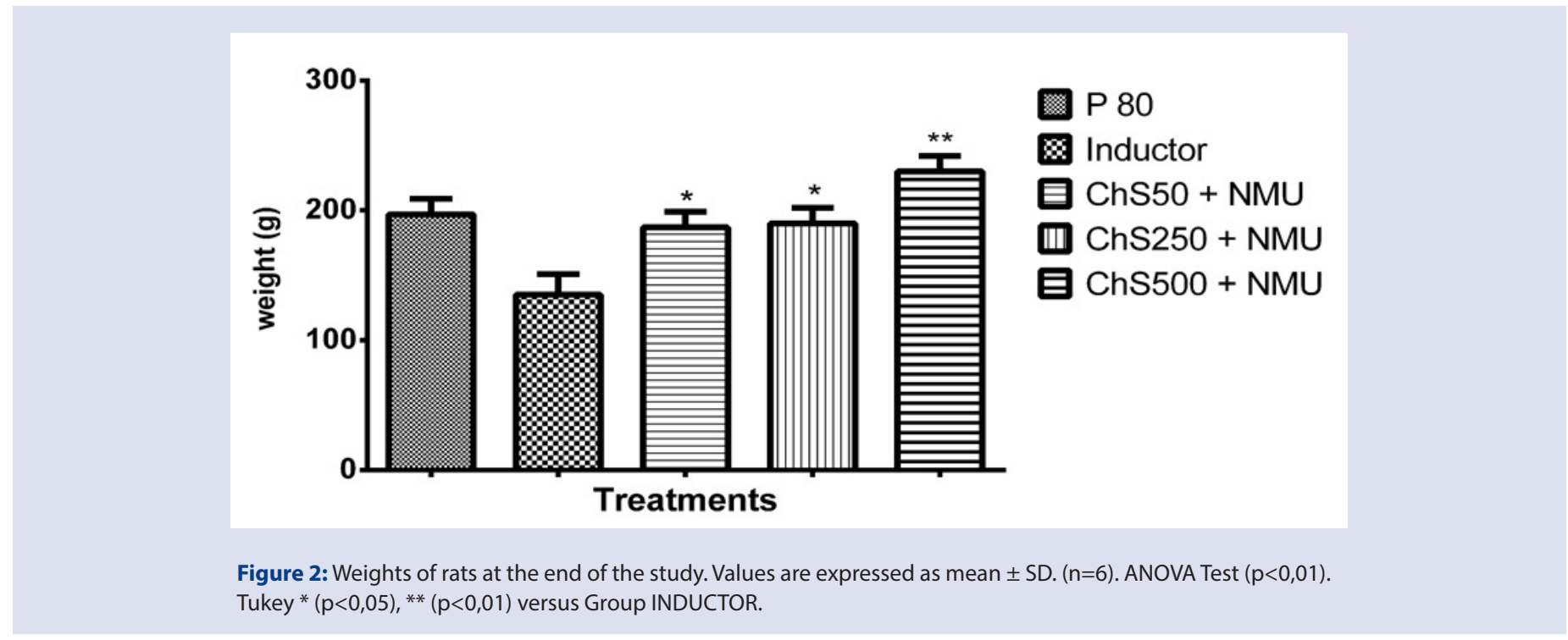

Hematological parameters showed a trend of increased HDL level and a decreased total cholesterol level in the group ChS 500 compared to the groups receiving the extract at lower doses. The lipid-lowering effect could directly influence the development of cancer because it has been evidenced in preclinical studies that statins show promising results in pancreatic, liver, colorectal and gastric cancer. ${ }^{22}$ They affect the cell division in cancer and expressed in the inhibition of proliferation, induction of apoptosis, autophagy, anti-invasion and anti-migratory effect..$^{23}$ The groups that received the extract showed significantly lower values of CRP and NO. The relationship between chronic inflammation and the development of tumors was studied by Landa and showed a close relationship between the inflammatory and the increased prevalence of cancer. ${ }^{24}$ The effect of ethanol extract of Ch. spinosa in reducing CRP, MDA, SOD and NO levels could be due to the presence of flavonoids, which have the property of reducing the inflammatory mediators, and significantly reduces the odds to develop a cancerous disease. ${ }^{25,26}$ The levels of MDA and SOD were significantly lower in treated groups
Table 1: Phytochemical constituents of the ethanolic extract of Chuquiraga spinosa.

\begin{tabular}{ccc}
\hline Constituents & Test & Result \\
\hline Alkaloids & Mayer & + \\
& Dragendorff & + \\
Wlavonoid & Wagner & + \\
Quinone & Shinoda & + \\
Phenols compounds & Bornträger & + \\
Saponins & Ferric chloride & + \\
Tannins & frothing & + \\
Terpenes and steroids & Gelatin & + \\
\hline
\end{tabular}


Table 2: Effect of Chuquiraga spinosa extract on hematological parameters

\begin{tabular}{|c|c|c|c|c|c|c|c|}
\hline $\begin{array}{l}\text { Parameter } \\
\text { treatment }\end{array}$ & Leukocytes & $\begin{array}{l}\text { Total cholesterol } \\
(\mathrm{mg} / \mathrm{ml})\end{array}$ & $\begin{array}{l}\text { HDL cholesterol } \\
(\mathrm{mg} / \mathrm{ml})\end{array}$ & ALT (mg/dl) & $\begin{array}{c}\text { ALP } \\
(\mathrm{mg} / \mathrm{mL})\end{array}$ & Bilirubin & Protein \\
\hline P80 & $6883.33 \pm 573.54$ & $161.17 \pm 11.30$ & $46.00 \pm 2.42$ & $31.17 \pm 2.96$ & $143.00 \pm 7.39$ & $0.68 \pm 0.08^{\alpha}$ & $5.25 \pm 0.31^{a}$ \\
\hline NMU $500 \mu \mathrm{g} / \mathrm{kg}$ & $7015.00 \pm 911.24$ & $156.67 \pm 9.93$ & $44.00 \pm 1.88$ & $63.67 \pm 7.30$ & $204.83 \pm 9.03$ & $2.43 \pm 0.18$ & $2.92 \pm 0.12$ \\
\hline $\mathrm{NMU}+\mathrm{ChS} 50$ & $8933.33 \pm 554.78$ & $171.33 \pm 13.54$ & $43.00 \pm 0.58$ & $25.33 \pm 5.81^{a}$ & $182.00 \pm 7.55$ & $1.43 \pm 0.13^{a}$ & $3.43 \pm 0.32^{\beta}$ \\
\hline $\mathrm{NMU}+\mathrm{ChS} 250$ & $7750.00 \pm 796.97$ & $159.33 \pm 8.32$ & $45.67 \pm 2.74$ & $52.83 \pm 5.55$ & $150.00 \pm 8.87$ & $2.01 \pm 0.16^{\beta}$ & $3.08 \pm 0.21^{\beta}$ \\
\hline $\mathrm{NMU}+\mathrm{ChS} 500$ & $7150.00 \pm 750.00$ & $169.50 \pm 15.70$ & $52.00 \pm 5.45^{a}$ & $25.75 \pm 3.22^{a}$ & $180.25 \pm 9.75$ & $2.12 \pm 0.25^{\beta}$ & $3.11 \pm 0.12^{\beta}$ \\
\hline
\end{tabular}

Values are expressed as mean \pm SD. $(n=6)$. ANOVA Test $(\mathrm{p}<0.01)$. Tukey a $(\mathrm{p}<0.01)$ versus Group INDUCTOR. $\beta$ ( $<<0,05)$ versus Group INDUCTOR

Table 3: Effect of Chuquiraga spinosa extract on biochemical parameters.

\begin{tabular}{ccccc}
\hline Treatment & $\begin{array}{c}\text { SOD } \\
(\mathrm{U} / \mathrm{mL})\end{array}$ & $\begin{array}{c}\text { MDA } \\
\left(10^{-6} \mathrm{~mol} / \mathrm{L}\right)\end{array}$ & $\begin{array}{c}\text { NO } \\
(\mu \mathrm{mol} / \mathrm{L})\end{array}$ & $\begin{array}{c}\text { CRP } \\
(\mathrm{U} / \mathrm{mL})\end{array}$ \\
\hline P 80 & $96,0 \pm 16,2^{\alpha}$ & $1,4 \pm 1,3^{\alpha}$ & $1,2 \pm 0,9^{a}$ & $0,5 \pm 0,2^{\alpha}$ \\
INDUCTOR & $364,8 \pm 23,9$ & $12,2 \pm 3,7$ & $147,0 \pm 43,7$ & $3,1 \pm 0,4$ \\
ChS 50 & $220,2 \pm 16,5^{\alpha}$ & $2,0 \pm 0,4^{\alpha}$ & $64,8 \pm 33,6^{\beta}$ & $1,2 \pm 0,7^{\alpha}$ \\
ChS 250 & $153,8 \pm 20,7^{\alpha}$ & $5,0 \pm 3,9^{a}$ & $54,9 \pm 31,1^{a}$ & $0,7 \pm 0,1^{\alpha}$ \\
ChS 500 & $112,2 \pm 14,6^{\alpha}$ & $4,0 \pm 2,3^{\alpha}$ & $94,7 \pm 25,2$ & $0,9 \pm 0,4^{\alpha}$ \\
\hline
\end{tabular}

Values are expressed' as mean \pm SD. $(n=6)$

ANOVA Test $(\mathrm{p}<0.01)$. Tukey $\alpha(\mathrm{p}<0.01)$ versus Group INDUCTOR. $\beta(\mathrm{p}<0.05)$ versus Group INDUCTOR

compared to inductor group. MDA is related to oxidative stress and oxidative degeneration, which is closely linked to the genesis of neoplasms and dysplasias. ${ }^{27}$

Casado found that reactive oxygen species (ROS) are important in the pathogenesis of cancer and cancer cells have many ROS that induces malignant phenotype. ${ }^{11}$ Landa also studied the antioxidant effect of Chuquiraga spinosa and found that its antioxidant activity is due to the flavonoid kaempferol. Chuquiraga spinosa is an anti-inflammatory and antioxidant agent and may have a protective effect for cancer. ${ }^{24} \mathrm{~A}$ significantly low level of MDA implicates potent antioxidant effect, and a significantly decreased CRP level indicates a strong anti-inflammatory effect. $^{28}$

The limitations of this study include the lack of isolated metabolites present in the Chuquiraga spinosa extract. Also, its exact mechanism of it is unclear. This study includes an Animal model and add to understand human pathology but can be extrapolated to human beings in the future. The data indicate the preventive potential in gastric cancer with a high therapeutic index. However, the complete mechanisms on which those effects are based are unknown. Further studies are needed to identify more precisely the active molecules involved in the protective effect described.

\section{CONCLUSION}

From the above results, it can be inferred that $\mathrm{ChS}$ at doses of $500 \mathrm{mg} / \mathrm{Kg}$ attenuated NMU-induced oxidative stress because of the antioxidant activity of its bioactive metabolites. Considering the antitumorigenic, hypolipidemic, anti-inflammatory and antioxidant properties of ChS, we conclude that it has a protective effect on NMU-induced gastric cancer in rats. There is a great potential to develop Chuquiraga spinosa as an alternative therapeutic agent in gastric cancer treatment, and hence further studies are needed, particularly clinical studies, to further evaluate this effect.

\section{ACKNOWLEDGEMENT}

The authors are thankful to Vicerrectorado de Investigación, Universidad Nacional Mayor de San Marcos. Lima, Peru.

\section{CONFLICT OF INTEREST}

There are no conflicts of interest.

\section{ABBREVIATION USED}

GC: gastric cancer; ChS: Chuquiraga spinosa; NMU: N-Methyl-NNitroso-Urea; NO: nitric oxide; MDA: malondialdehyde; SOD: superoxide dismutase; CRP: C-reactive protein; ALP: Alkaline Phosphatase; ALT: Alanine transaminase.

\section{REFERENCES}

1. Kang C, Song JJ, Lee J, Kim MY, Epigenetics: an emerging player in gastric cancer, World J Gastroenterology 2014;20:6433-47.

2. Cunningham D, Allum WH, Stenning SP, Thompson JN, Van de Velde CJ, Nicolson $\mathrm{M}$, et al. Perioperative chemotherapy versus surgery alone for resectable gastroesophageal cancer. New England Journal of Medicine. 2006;355(1):11-20.

3. Sakuramoto S, Sasako M, Yamaguchi T, Kinoshita T, Fujii M, Nashimoto A, et al. Adjuvant chemotherapy for gastric cancer with S-1, an oral fluoropyrimidine. New England Journal of Medicine. 2007;357(18):1810-20.

4. Mendoza D, Herrera P, Gilman RH, Lanfranco J, Tapia M, Bussalleu A. et al. Variation in the prevalence of gastric cancer in Peru. International journal of cancer 2008;123(2):414-20

5. Dulak AM, Schumacher SE, van Lieshout J, Imamura Y, Fox C, Shim B, et al. Gastrointestinal adenocarcinomas of the esophagus, stomach, and colon exhibit distinct patterns of genome instability and oncogenesis. Cancer research. 2012;72(17):4383-93.

6. Arroyo-Acevedo J, Herrera-Calderón O, Chávez-Asmat R, Anampa-Guzmán A Chumpitaz-Cerrate V, Enciso-Roca E. Protective effect of Chuquiraga spinosa extract on $\mathrm{N}$-methyl-nitrosourea (NMU) induced prostate cancer in rats. Prostate international. 2017;5(2):47-52.

7. Herrera-Calderon O, Santiváñez-Acosta R, Pari-Olarte B, Enciso-Roca E, Montes VM, Acevedo JL. Anticonvulsant effect of ethanolic extract of Cyperus articulatus L. leaves on pentylenetetrazol induced seizure in mice. Journal of Traditional and Complementary Medicine. 2017; 20.

8. Herrera-Calderon O, Enciso-Roca E, Pari-Olarte B, Arroyo-Acevedo J. Phytochemical screening, antioxidant activity and analgesic effect of Waltheria ovata Cav. roots in mice. Asian Pacific Journal of Tropical Disease. 2016;6(12):1000-3

9. Herrera-Calderon O, Tinco-Jayo JA, Franco-Quino C, Chumpitaz-Cerrate V, Castro-Pari W, Pari-Olarte B, et al. Antioxidant activity and cytotoxic profile of Chuquiraga spinosa Lessing on human tumor cell lines: A promissory plant from Peruvian flora. Asian Pac J Trop Dis. 2017;7(5):304-8.

10. Alberto MR, Zampini IC, Isla MI. Inhibition of cyclooxygenase activity by standardized hydroalcoholic extracts of four Asteraceae species from the Argentine Puna. Braz J Med Biol Res 2009 42(9):776-869.

11. Casado R, Landa A, Calvo J, García-Mina JM, Marston A, Hostettmann K, Calvo MI. Anti-inflammatory, antioxidant and antifungal activity of Chuquiraga spinosa. Pharm Biol 2011;49(6):620-6.

12. Trease E, Evans WC. Trease and Evans' pharmacognosy. 15th ed. San Diego: Harcourt Publishers Limited; 2002, p. 343-45.

13. Tatematsu M, Ogawa K, Hoshiya T, Shichino Y, Kato T, Imaida K, et al. Induction of adenocarcinomas in the glandular stomach of BALB/C mice treated with N-methyl-N-nitrosourea. Jpn J Cancer Res 1992; 83:915-8.

14. Beauchamp C, Fridovich I. Superoxide dismutase: improved assays and an assay applicable to acrylamide gels. Anal Biochem 1971; 44:276-287.

15. Buege J, Aust S. Microsomal lipid peroxidation. Methods Enzymol. 1978;52: 
302-310.

16. Miranda KM, Espey MG, David A. A rapid, simple spectrophotometric method for simultaneous detection of nitrate and nitrite. Nitric Oxide 2001;5(1): 62-71.

17. Peltola $H$, Laipio ML, Siimes MA. Quantitative C-reactive protein (CRP) determined by an immunoturbidimetric method in rapid differential diagnosis of acute bacterial and viral diseases of children. Acta Paediatr Scand. 1984;73(2): 273-4.

18. Corcos L, Le Jossic-Corcos C. Statins: perspectives in cancer therapeutics. Dig Liver Dis 2013;45(10):795-802.

19. Berstein LM. Clinical usage of hypolipidemic and antidiabetic drugs in the prevention and treatment of cancer. Cancer Lett 2005;224(2):203-12.

20. Pisanti S, Picardi P, Ciaglia E, D'Alessandro A, Bifulco M. Novel prospects of statins as therapeutic agents in cancer. Pharmacol Res 2014;88:84-98

21. Li Q, Jia Z, Wang L, Kong X, Li Q, Guo K, et al. Disruption of Klf4 in villin-positive gastric progenitor cells promotes formation and progression of tumors of the antrum in mice. Gastroenterology 2012;142:531-42

22. Zi X, Grasso AW, Kung HJ, Agarwal RA. Flavonoid antioxidant, silymarin, inhibits activation of erbB1 signaling and induces cyclin-dependent kinase inhibitors, G1 arrest, and anticarcinogenic effects in human prostate carcinoma DU145 cells Cancer Res 1998;58(9):1920-9.

23. Simsek N, Kaya M, Kara A, Can I, Karadeniz A, Kalkan Y. Effects of melatonin on islet neogenesis and beta cell apoptosis in streptozotocin-induced diabetic rats: an immunohistochemical study. Domest Anim Endocrinol 2012;l;43(1):47-57.

24. Landa A, Casado R, Calvo MI. Identification of flavonoids from Chuquiraga spinosa, (Asteraceae). Nat Prod Commun 2009:4(10):1353-5.

25. Lee JY, Kim N, Choi YJ, Nam RH, Choi YJ, Kwon YH, et al. Histologic findings and inflammatory reactions after long-term colonization of Helicobacter felis in C57BL/6 mice. J Cancer Prev 2014; 19:224-30.

26. Tomita H, Takaishi S, Menheniott TR, Yang X, Shibata W, Jin G et al. Inhibition of gastric carcinogenesis by the hormone gastrin is mediated by suppression of TFF1 epigenetic silencing. Gastroenterology. 2011;140(3):879-91.

27. Harlev E, Nevo E, Lansky EP, Lansky S, Bishayee A. Anticancer attributes of desert plants: a review. Anti-Cancer Drugs. 2012;23(3):255-71.

28. Deghrigue M, Lajili S, Turki M, Eltaief N, Bouraoui A. Evaluation of anti-inflammatory, analgesic and gastroprotective activities of Eunicella singularis fractions using in vivo assays. Ann Med Biomed Sci 2015;1(1):23-8.

\section{GRAPHICAL ABSTRACT}

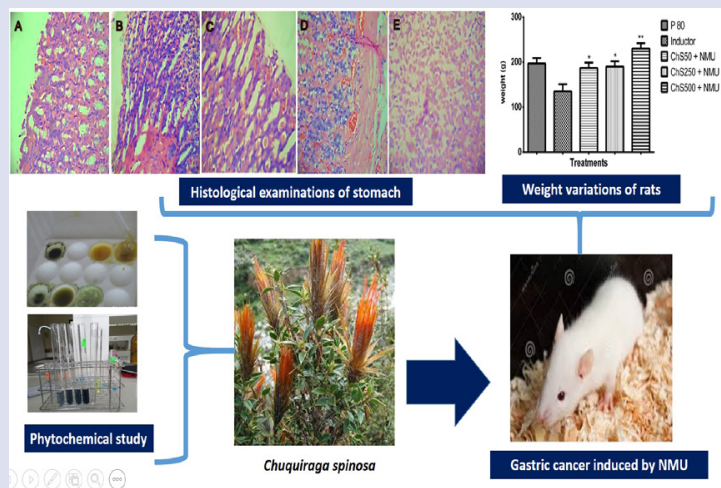

\section{SUMMARY}

- Chuquiraga spinosa has excellent anticancer properties on gastric cancer induced by NMU.

- $\mathrm{NMU}$ at $50 \mu \mathrm{g} / \mathrm{mL}$ induced moderated dysplasia in rats.

- Preliminary phytochemical analysis revealed the presence of phenolic compounds, flavonoids, alkaloids, triterpenes and steroids.

- Chuquiraga spinosa has antioxidant properties and positive effect on Malondialdehyde, nitric oxide and C-reactive protein levels.

- Gastric cancer was induced by oral gavage of NMU for 16 weeks.

\section{ABOUT AUTHORS}

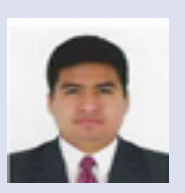

Oscar Herrera-Calderon: He is a professor and researcher in the Faculty of Pharmacy and Biochemistry, Universidad Nacional San Luis Gonzaga de Ica, Peru. His expertise is Natural products with anticancer properties, pharmacokinetic studies and the use of animals models to discover new potential drugs as antitumor.

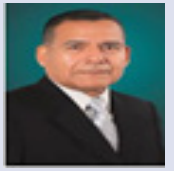

Jorge Luis Arroyo-Acevedo: Currently, $\mathrm{He}$ is the Head of the Laboratory of Experimental Pharmacology. Professor and researcher in the Faculty of Medicine, Universidad Nacional Mayor de San Marcos, Peru. His expertise is Natural products with medicinal properties and the use of animal models to discover new potential drugs.

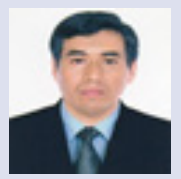

Juan Rojas-Armas: He is a professor and researcher in the Faculty of Medicine, Universidad Nacional Mayor de San Marcos. His expertise is Natural products with medicinal properties and the use of animal models to discover new potential drugs.

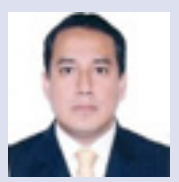

Victor Chumpitaz-Cerrate: He is a professor and researcher in the Faculty of Dentistry and Pharmacy, Universidad Nacional Mayor de San Marcos, Peru. His expertise is biochemical studies and the use of animal models to discover new potential drugs

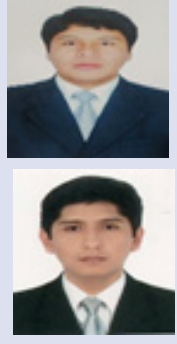

Renan Hañari-Quispe: He works in the Laboratory of Animal Physiology, Universidad Andina Nestor Caceres Velasquez, Peru. His expertise is Natural products with medicinal properties and the use of animal models to discover new potential drugs.

César Franco-Quino: He is a professor and researcher in the Faculty of Dentistry, Universidad Nacional Mayor de San Marcos, Peru. He is working with animal models to discover new drugs with different effects on nervous systems. Currently, He has a master in experimental pharmacology.

Cite this article: Arroyo-Acevedo J, Herrera-Calderón O, Rojas-Armas J, Chumpitaz-Cerrate V, Franco-Quino C, Hañari-Quispe R. Chuquiraga spinosa Lessing: A Medicinal Plant for Gastric Cancer Induced By N-Methyl-N-Nitroso-Urea (NMU).. Pharmacog J. 2018;10(1):20-4. 